\title{
Phlebotomine Sand Flies from São Gabriel da Cachoeira (State of Amazonas, Brazil) with a Description of Lutzomyia (Psychodopygus) douradoi n. sp. (Diptera: Psychodidae)
}

\author{
Nelson F Fé, Rui Alves de Freitas*, Toby V Barrett*/+
}

\begin{abstract}
Núcleo de Entomologia, Instituto de Medicina Tropical do Amazonas, Av. Pedro Teixeira s/no, 69040-000
Manaus, AM, Brasil *Coordenação de Pesquisas em Ciências da Saúde, Instituto Nacional de Pesquisas da Amazônia, Caixa Postal 478, 69011-970 Manaus, AM, Brasil
\end{abstract}

Thirty-five species of Lutzomyia and two species of Brumptomyia were identified among 795 phlebotomines taken in light-traps near the upper reaches of the middle Rio Negro. The subgenus Psychodopygus predominated in number of species (11) and relative abundance (74-81\% in light trap samples from the forest and 99\% on human bait). For many of the species these records help to fill large gaps on current maps of distribution, and for others (L. olmeca nociva, L. mangabeirana, L. triacantha) the findings represent a significant expansion of their known range. A new species in the subgenus Psychodopygus (L. douradoi) is described from both sexes, and L. bettinii is recorded for the first time in Brazil.

Key words: Neotropical Psychodidae - Brumptomyia - Lutzomyia - Lutzomyia douradoi - new species distribution - Amazônia

The extreme northwest of Brazil between the Colombian and Venezuelan borders is poorly represented in collections of Phlebotominae, and the main original contribution to records for the upper and middle Rio Negro region is a list of 22 species identified among 283 sand flies collected in southern Território Federal Amazonas, Venezuela (Feliciangeli et al. 1988). The rapids at São Gabriel da Cachoeira conventionally mark the division between the upper (alto) and middle (médio) Rio Negro and even a small collection from this area $\left(67^{\circ} \mathrm{W}\right.$ on the equator) can contribute to filling substantial gaps in current maps of species distribution (Young \& Duncan 1994). Opportunities for collection were provided by participation in an environmental impact study for a small hydroelectric project in this area in 1994, and subsequently by the Fundação Oswaldo Cruz (Fiocruz) expedition in 1995, during which a new species of sand fly was encountered. The purpose of the first part of this work is to make available the name and description of this new species for faunistic and parasitological studies in progress.

\footnotetext{
Work supported in part by INPA project PPI-3180, CNPq grant 520164/93, and Fiocruz project "Revisitando a Amazônia de Carlos Chagas: da Borracha à Biodiversidade".

${ }^{+}$Corresponding author. Fax: +55-92-643.3061

Received 19 November 1997

Accepted 15 January 1998
}

\section{MATERIALS AND METHODS}

Study areas - São Gabriel da Cachoeira: terra firme rain forest around Cachoeira Miuá on Igarapé Miuá, east of the Rio Negro at $0^{\circ} 7^{\prime} 00^{\prime \prime S}$, $66^{\circ} 53^{\prime} 00^{\prime \prime} \mathrm{W}$ and primary forest between this point and the town of São Gabriel da Cachoeira and the port of Camanaus. São José: primary terra firme rain forest near the community of São José, on the east bank of the Rio Negro at $0^{\circ} 18^{\prime} \mathrm{S}, 66^{\circ} 33^{\prime} \mathrm{W}$. Morro da Fortaleza: rocks among scrub vegetation at the top of Morro da Fortaleza, a granite outcrop at the edge of the town of São Gabriel.

Sampling - Battery-operated light traps were set at 1, 5, 7, 10 and $12 \mathrm{~m}$ above the forest floor at São José and at $1 \mathrm{~m}$ elsewhere. Most of the São Gabriel sample was collected around Cachoeira Miuá at the beginning of March 1994, and the São José specimens were collected in August, September and the end of November 1995. Human bait collections were carried out between 18:00 and 20:00 hr local time. Dominance indices in the Table are number of specimens of the respective taxa divided by total number of phlebotomines collected in light traps at each location.

Systematics - Terminology and classification follows Young and Duncan (1994) except for their broad definition of Lutzomyia infraspinosa (Mangabeira). Measurements are mean values in $\mathrm{mm}$ with range in parentheses and are for specimens cleared in $\mathrm{NaOH}$ and phenol and mounted in Canada balsam. For differential diagnosis, females of $L$. douradoi were compared with $L$. chagasi collected in the same area (Fig. 11). 


\section{TAXONOMIC DESCRIPTION}

Lutzomyia douradoi Freitas \& Fé, n.sp.

(Figs 1-10, 12).

Male: wing length 1.84(1.78-1.92), width $0.53(0.51-0.55)$. Length of insect 2.3. General colour dark brown, dark mesonotum contrasting with pale pleura and coxae. Head height from vertex to tip of clypeus 0.33 , width $0.37(0.36-0.38)$. Eyes separated by $0.08(0.08-0.09)$ equivalent to 4.4 facet diameters. Interocular suture incomplete. Flagellomere I 0.27(0.25-0.29) long, II+III $0.22(0.21-0.23)$; ascoids simple with slight posterior spur, their tips usually reaching apex of flagellomere and visible on all flagellomeres except the distal 2 or 3. Labrum 0.20(0.18-0.20) long. Length of palps $0.33(0.32-0.34)$, length of palpomeres: $1,0.03 ; 2,0.09(0.08-0.09) ; 3$, $0.13(0.12-0.13)$; 4, 0.04; 5, 0.05; palpal sensilla along internal face of third palpomere only, below subapical spine, usually confined to distal fourfifths of structure. Cibarium unarmed, pigment patch very slender and ill-defined; arch incomplete or apparent only at sides. Pharynx 0.19(0.18-0.20) long, unarmed, finely striated in posterior third. Thorax $0.57(0.55-0.59)$ from anterior margin of mesonotum to tip of scutellum. Median process of prescutum elongate, claw-like; 0.075 long, surpassing anterior margin of mesonotum by 0.05 . Pleura with 26(22-29) episternal setae, of which 19(15-22) upper and 7(4-8) lower. Length of wing-vein sections: alpha $0.50(0.45-0.54)$, beta $0.24(0.21-0.26)$, gamma 0.16(0.15-0.19), delta 0.28(0.25-0.31). Legs without spines. Length of femora, tibiae and basitarsi: foreleg, 0.76(0.73-0.80), 1.11(1.06-1.16), 0.72(0.70-0.77); midleg, 0.72(0.67-0.75), 1,27(1.211.35), 0.80(0.77-0.84); hindleg 0.84(0.78-0.87), 1.47(1.36-1.53), 0.86(0.81-0.91). Abdomen 1.74 (1.72-1.77) long. Genitalia: style 0.19 long, 0.05 (0.05-0.06) wide, with a single recurvate apical spine and three distal setae. Coxite 0.27(0.26-0.28) long, 0.15(0.14-0.16) wide, with median constriction. Paramere complex, turned upwards and inwards distally in the form of an inverted boot, ventral margin sinuous; dorsally with a subtransverse palisade of six stout setae at level of aedeagus converging proximally with that on opposite paramere, and a subterminal arm arising from the ventral lateral side of the structure. Apex of dorsal arm of paramere pointed, with a long inner and short outer foliaceous projection directed downward and three hair-like setae; base of arm with a row of three straight setae. Aedeagus long, conical, moderately pigmented. Genital pump 0.19 long, each filament 0.40 long or twice length of pump; filament tips distinctly dilated. Lateral lobe 0.26(0.25-0.27) long, simple, subcylindrical. Cerci normal.
Female: wing length 2.19(2.12-2.24), width 0.62(0.59-0.67). Length of insect 2.55(2.53-2.59). Colouration as in male. Head height 0.43(0.40$0.45)$, width $0.41(0.36-0.43)$. Eyes separated by $0.11(0.10-0.12)$ equivalent to 5.8 facet diameters. Interocular suture incomplete. Flagellomere I 0.28(0.25-0.30) long, II + III 0.23(0.21-0.24); ascoids as in male, visible on all flagellomeres except the distal 2. Labrum 0.46(0.40-0.48) long. Length of palps $0.60(0.52-0.62)$, length of palpomeres: $1,0.06(0.05-0.06) ; 2,0.20(0.16-0.21)$; $3,0.23(0.19-0.24) ; 4,0.05(0.04-0.06) ; 5,0.07$ (0.06-0.08); palpal sensilla as in male. Cibarium with four sharp horizontal teeth, the distance between the middle two slightly greater than between these and the outer teeth; about 15(13-19) vertical teeth arranged in one tranverse arc at base of horizontal teeth and two irregular longitudinal rows; pigment patch wide, subtriangular, poorly defined; arch inapparent or incomplete. Pharynx 0.21(0.190.22 ) long, with ridges in the posterior third. Tho$\operatorname{rax} 0.61(0.59-0.61)$ long. Prescutum as in male. Pleura with 29(24-34) episternal setae, of which 21(18-23) upper and 8(6-11) lower. Length of wing-vein sections: alpha $0.61(0.58-0.67)$, beta 0.25(0.24-0.29), gamma 0.21(0.15-0.24), delta $0.36(0.27-0.41)$. Legs without spines. Length of femorae, tibiae and basitarsi: foreleg, 0.84(0.80$0.90), 1.22(1.13-1.27), 0.77$ (0.72-0.82); midleg, 0.80 (0.78-0.82), 1,41(1.36-1.48), 0.87(0.85-0.93); hindleg 0.92(0.87-0.95), 1.58(1.53-1.65), 0.93 (0.86-1.00). Abdomen 1.94 (1.92-1.98) long. Spermathecae with eight imbricated annulations, body 0.04 long and slightly less than half as wide; head 0.012 long and half as wide; individual ducts 0.15 long, $5 \mathrm{X}$ length and half width of common duct, smooth on basal and rugose on distal halves. Stem of genital fork long and pointed. Cerci normal.

Material examined - Brazil, Amazonas, São Gabriel da Cachoeira, Comunidade São José, east bank of the Rio Negro at $0^{\circ} 18^{\prime} \mathrm{S}, 6^{\circ} 33^{\prime} \mathrm{W}$, light traps. Holotype male 16.8.95, Allotype female 28.11.95 at $10 \mathrm{~m}, \mathrm{~N}$. Fé. Other Paratypes, 10 males and 12 females, Aug-Nov. 1995. The holotype will be deposited in the entomology collections at INPA. Paratypes will be sent to the Fiocruz collection at the Centro de Pesquisas René Rachou, Belo Horizonte, Brazil.

We are pleased to name this species in honour of our friend and colleague Dr Heitor Vieira Dourado, co-founder of IMT-AM, for his outstanding contributions to the fields of Public Health and Higher Education in the Amazon Region.

Remarks - The male genitalia of L. douradoi place this species in the squamiventris series of the subgenus Psychodopygus. The shape of the end of the main lobe of the paramere is diagnostic in $L$. 


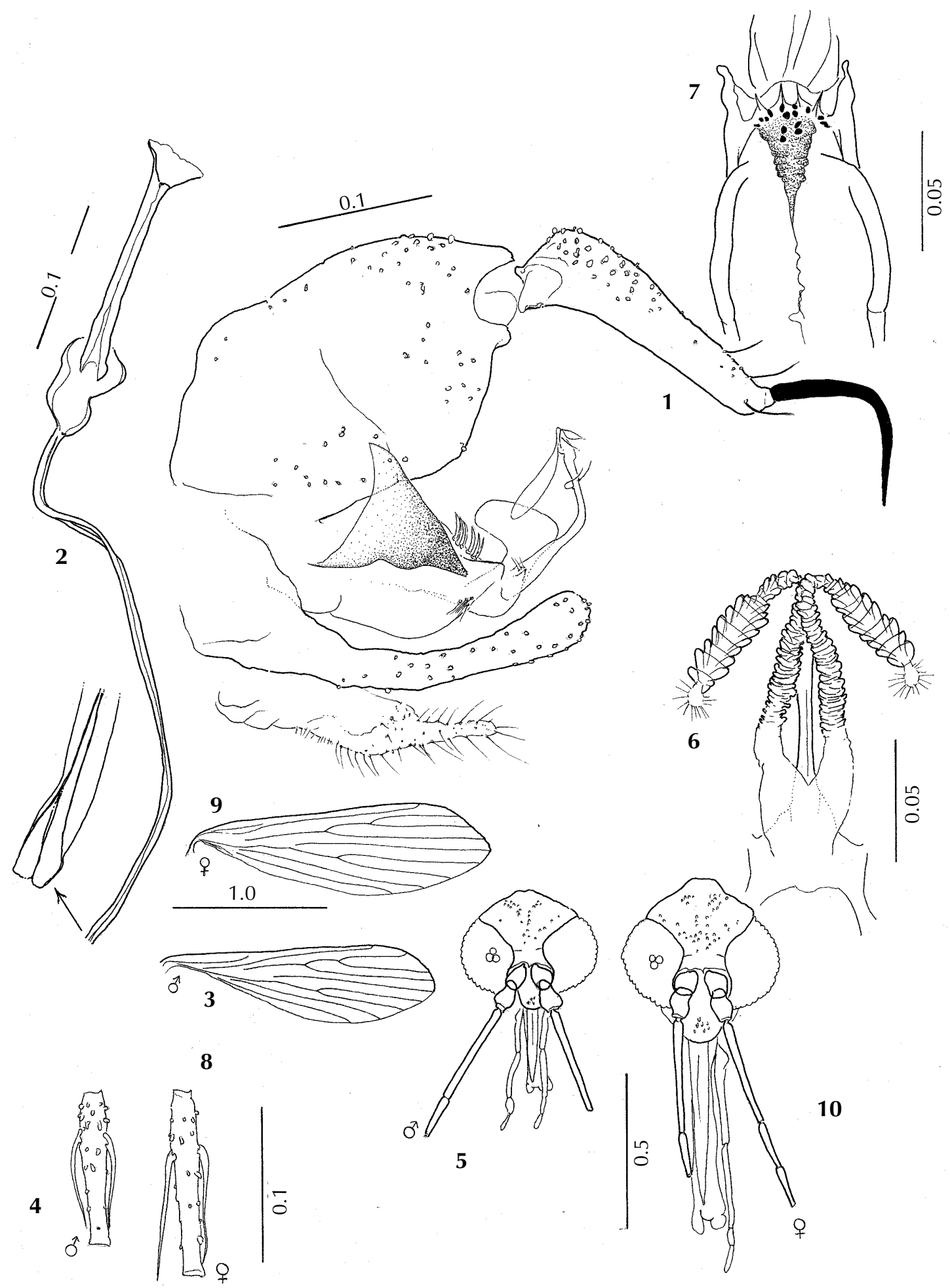

Lutzomyia douradoi n.sp. Figs 1-5: holotype male. Figs 6-10: allotype. Fig. 1: terminalia. Fig. 2: genital pump and filaments. Fig. 3: wing. Fig. 4: flagellomere II. Fig. 5: head. Fig. 6: spermathecae. Fig.7: cibarium. Fig. 8: flagellomere II. Fig. 9: wing. Fig. 10: head. 
douradoi and the male is unlikely to be confused with any other known species of Lutzomyia. Males and females of the new species were taken together in the same traps, and association of sexes was based on the form of the median process of the prescutum, i.e., the junction of the anterior paratergites.

The process of the prescutum (Figs 11, 12) is long, narrow and unguinate in $L$. douradoi, whereas in $L$. chagasi this structure forms a broad-based triangle in dorsal view, the apex not surpassing the mesonotum along the long axis of the insect. The female of $L$. douradoi is otherwise very close to $L$. chagasi and other species (L. squamiventris, $L$. complexa, L. wellcomei, L. fairtigi and L. killicki) in which the spermatheca is shorter than the individual sperm duct and the common duct is entirely hyaline. The ratio of the lengths of spermatheca including head: individual duct: common duct is approximately 1:3:0.6 in $L$. douradoi and closer to 1:2:1 in descriptions of the other species (Martins et al. 1968, Fraiha et al. 1971, Ryan 1986, Feliciangeli et al. 1988; measurements unavailable for L. fairtigi). The common duct and basal halves of the individual sperm ducts are so transparent in this group that they can be difficult to see in cleared and mounted specimens, but their relative lengths should be a useful diagnostic character for $L$. douradoi in material being examined for leishmanial and other parasites.

L. douradoi groups with $L$. chagasi for the number of vertical cibarial teeth and the length of the first flagellomere (Martins et al. 1968) and therefore differs from $L$. squamiventris for these characters. Neither $L$. douradoi nor $L$. chagasi present the very short basitarsi on the fore - and midlegs described for L. killicki by Feliciangeli et al. (1988).

L. douradoi is the only species of Psychodopygus that has been described since Young and Duncan (1994) published their keys to the subgenus, and the new species keys out with $L$. fairtigi for both sexes. The males can be separated by the bulbous end of the main lobe of the paramere: strongly upturned (L. douradoi)/not upturned ( $L$. fairtigi). The females are not separable on the basis of available descriptions of $L$. fairtigi.

\section{RESULTS}

The light trap samples are described in the Table. Samples from the forest were strongly dominated $(74.1 \%$ and $81.5 \%)$ by species of the subgenus Psychodopygus, whereas the small sample from Morro da Fortaleza was dominated by Brumptomyia spp. (21.2\%) and the subgenus Nyssomyia (39.4\%). All specimens identified as $L$. douradoi (32 males and 52 females) were taken at $10 \mathrm{~m}$ height at São José (eight trap-nights).

Human bait catches on five nights in the forest around Cachoeira Miuá yielded only 110 sand flies (mean 3.7 per man-hour, maximum 10.8 per manhour on the night with the largest sample) distributed as follows: L. (Psychodopygus) chagasi $58=53 \% ; L .(P)$ paraensis $32=29 \% ; L .(P)$ ayrozai $11 ;$ L. $(P)$ geniculata $4 ; L$. $(P)$ carrerai $2 ; L .(P)$
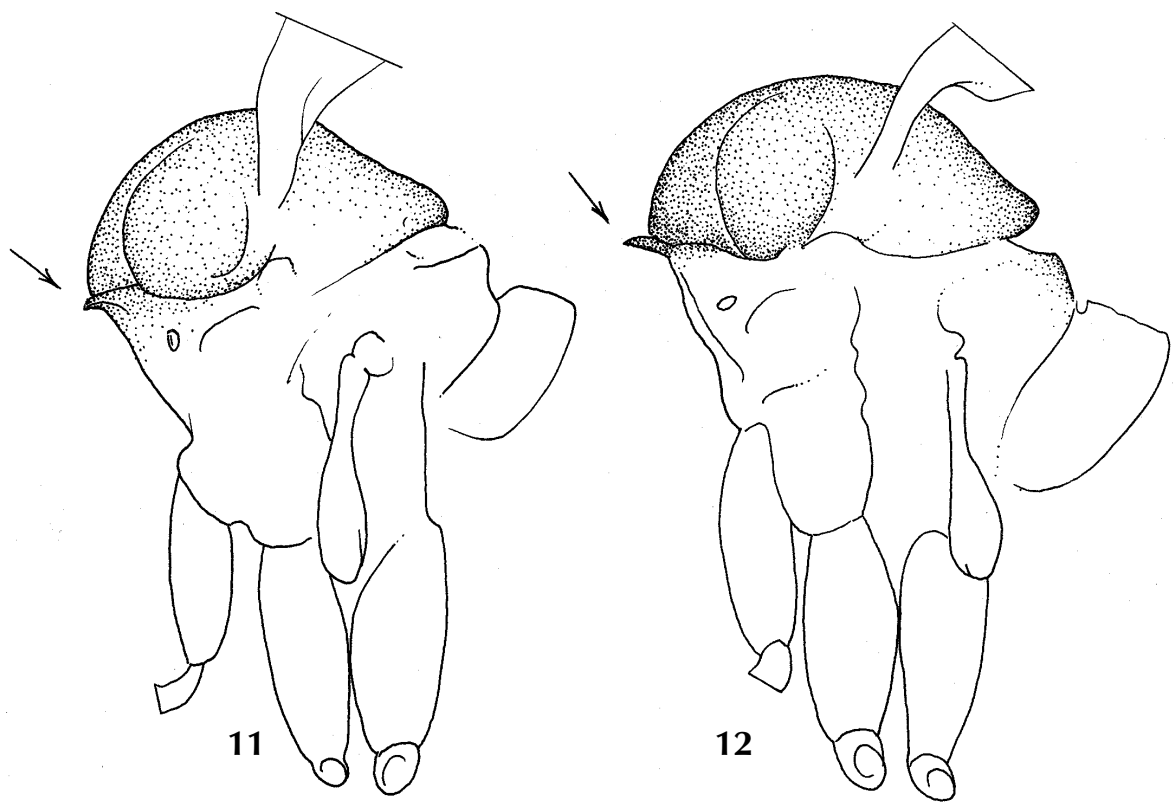

Thorax with lateral view of prescutum, females. Fig. 11: Lutzomyia chagasi (Costa Lima); São Gabriel da Cachoeira. Fig. 12: Lutzomyia douradoi $\mathrm{n} . \mathrm{sp}$. 
TABLE

Phlebotominae collected in light traps near the town of São Gabriel da Cachoeira (Middle Rio Negro, Amazonas, Brazil) 1994-1995

\begin{tabular}{|c|c|c|c|c|c|c|}
\hline \multirow[b]{2}{*}{ Taxa } & \multicolumn{3}{|c|}{ Location $^{a}$} & \multirow[b]{2}{*}{$\mathrm{T}$} & \multirow[b]{2}{*}{$\mathrm{M}$} & \multirow[b]{2}{*}{$\mathrm{F}$} \\
\hline & S. Gabriel & S. José & M. Fortaleza & & & \\
\hline \multicolumn{7}{|c|}{ BRUMPTOMYIA Genus $b$} \\
\hline *B. pintoi & 0 & 0 & 1 & 1 & 1 & 0 \\
\hline *B. pentacantha & 0 & 0 & 13 & 13 & 9 & 4 \\
\hline \multicolumn{7}{|l|}{ LUTZOMYIA Genus } \\
\hline \multicolumn{7}{|l|}{ Lutzomyia subgenus } \\
\hline *L. spathotrichia & 0 & 1 & 0 & 1 & 0 & 1 \\
\hline$*$ L. gomezi & 0 & 0 & 2 & 2 & 0 & 2 \\
\hline \multicolumn{7}{|l|}{ Sciopemyia subgen. } \\
\hline L. sordellii & 19 & 0 & 0 & 19 & 5 & 14 \\
\hline \multicolumn{7}{|l|}{ L. migonei group } \\
\hline${ }^{*}$ L. williamsi & 0 & 1 & 0 & 1 & 0 & 1 \\
\hline$*$ L. sericea & 0 & 1 & 1 & 2 & 2 & 0 \\
\hline L. walkeri & 1 & 2 & 0 & 3 & 1 & 2 \\
\hline \multicolumn{7}{|l|}{ L.verrucarum group } \\
\hline${ }^{*}$ L. serrana & 1 & 0 & 0 & 1 & 0 & 1 \\
\hline \multicolumn{7}{|l|}{ Pressatia subgenus } \\
\hline$*$ L. triacantha & 0 & 2 & 0 & 2 & 1 & 1 \\
\hline \multicolumn{7}{|c|}{ Evandromyia subgenus } \\
\hline Lutzomyia $\mathrm{sp}^{c}$ & 8 & 4 & 14 & 26 & 7 & 19 \\
\hline L. monstruosa & 15 & 0 & 0 & 15 & 5 & 10 \\
\hline \multicolumn{7}{|l|}{ Psathyromyia subgen. } \\
\hline L. lutziana & 2 & 0 & 1 & 3 & 3 & 0 \\
\hline \multicolumn{7}{|l|}{ L. aragaoi group } \\
\hline$*$ L. runoides & 0 & 8 & 0 & 8 & 5 & 3 \\
\hline \multicolumn{7}{|l|}{ L. dreisbachi group } \\
\hline L. dreisbachi & 15 & 0 & 0 & 15 & 4 & 11 \\
\hline \multicolumn{7}{|l|}{ Nyssomyia subgenus } \\
\hline L. flaviscutellata & 15 & 21 & 2 & 38 & 9 & 29 \\
\hline${ }^{*}$ L. reducta & 7 & 0 & 0 & 7 & 0 & 7 \\
\hline *L. olmeca nociva & 0 & 1 & 0 & 1 & 1 & 0 \\
\hline L. antunesi & 0 & 1 & 0 & 1 & 0 & 1 \\
\hline L. anduzei & 1 & 2 & 7 & 10 & 2 & 8 \\
\hline L. umbratilis & 0 & 1 & 0 & 1 & 0 & 1 \\
\hline L. yuilli yuilli & 10 & 8 & 17 & 35 & 8 & 27 \\
\hline \multicolumn{7}{|c|}{ Trichophoromyia subgen. } \\
\hline L. ubiquitalis & 0 & 5 & 0 & 5 & 3 & 2 \\
\hline **L. bettinii & 2 & 0 & 0 & 2 & 2 & 0 \\
\hline \multicolumn{7}{|c|}{ Psychogodopygus subgen. } \\
\hline L. bernalei & 15 & 3 & 0 & 18 & 17 & 1 \\
\hline${ }^{*}$ L. chagasi & 93 & 53 & 0 & 146 & 60 & 86 \\
\hline$* *$ L. douradoi & 0 & 84 & 0 & 84 & 32 & 52 \\
\hline${ }^{*}$ L. bispinosa & 2 & 0 & 0 & 2 & 0 & 2 \\
\hline L. corossoniensis & 1 & 0 & 0 & 1 & 0 & 1 \\
\hline${ }^{*}$ L. geniculata & 19 & 1 & 3 & 23 & 1 & 22 \\
\hline L. davisi & 37 & 41 & 4 & 82 & 17 & 65 \\
\hline L. amazonensis & 0 & 4 & 0 & 4 & 1 & 3 \\
\hline L. paraensis & 36 & 0 & 0 & 36 & 6 & 30 \\
\hline L. ayrozai & 83 & 78 & 0 & 161 & 69 & 92 \\
\hline $\begin{array}{l}\text { L. carrerai carrerai } \\
\text { L. pilosa } \text { group }^{b}\end{array}$ & 14 & 0 & 0 & 14 & 8 & 6 \\
\hline *L. pilosa & 0 & 0 & 1 & 1 & 1 & 0 \\
\hline${ }^{*}$ L. mangabeirana & 9 & 2 & 0 & 11 & 3 & 8 \\
\hline
\end{tabular}




\begin{tabular}{|c|c|c|c|c|c|c|}
\hline & \multicolumn{3}{|c|}{ Location $^{a}$} & \multirow[b]{2}{*}{$\mathrm{T}$} & \multirow[b]{2}{*}{ M } & \multirow[b]{2}{*}{$\mathrm{F}$} \\
\hline & S. Gabriel & S. José & M. Fortaleza & & & \\
\hline \multicolumn{7}{|l|}{ (Totals) } \\
\hline Trap-nights & 77 & 28 & 3 & 108 & - & - \\
\hline Individuals & 405 & 324 & 66 & 795 & 283 & 512 \\
\hline Species & 22 & 22 & 12 & 37 & - & - \\
\hline \multicolumn{7}{|l|}{ (Dominance indices) } \\
\hline Psychodopygus Subgen. & 0.741 & 0.815 & 0.106 & - & - & - \\
\hline L. (P.) ayrozai & 0.205 & 0.241 & 0.000 & - & - & - \\
\hline L. $(P$.$) chagasi$ & 0.230 & 0.164 & 0.000 & - & - & - \\
\hline L. (P.) davisi & 0.091 & 0.127 & 0.061 & - & - & - \\
\hline L. (P.) douradoi & 0.000 & 0.259 & 0.000 & - & - & - \\
\hline L. (P.) paraensis & 0.089 & 0.000 & 0.000 & - & - & - \\
\hline Nyssomyia Subgen. & 0.081 & 0.105 & 0.394 & - & - & - \\
\hline
\end{tabular}

T: total. M: males. F: females. $a$ : locations described in text. $b$ : females of the species found appear to be indistinguishable. c: L. begonae - sensu Young and Arias 1977 Acta Amazonica 7: 59-70, nec Ortiz and Torres; treated as a variant of $L$. infraspinosa (Mangabeira) by Young and Duncan (1994). *: species not registered for this area in maps of Young and Duncan (1994). **: new record for Brazil.

amazonensis, L. $(P)$ corossoniensis and $L$. (Nyssomyia) anduzei one each.

\section{DISCUSSION}

The finding of a new species in the squamiventris series once again drew attention to the problem of identifying females of this medically important group. Our initial difficulty in establishing a diagnosis for the female of $L$. douradoi was due at least in part to the lack of adequate descriptions of the females of other species with which it could be confused - a reasonably complete description was available only for $L$. killicki.

The 35 species of Lutzomyia in this collection from São Gabriel da Cachoeira include 19 of the 22 species identified in samples from southern Território Federal Amazonas, Venezuela (Feliciangeli et al. 1988). The remaining three species in that collection (L. furcata, L. tuberculata, L. shannoni) are widely distributed in northern South America.

Our material of $L$. triacantha consists of one female and one male, the paramere and coxite base of the latter agreeing well with fig. $119 \mathrm{~B}$ of Young and Duncan (1994). Females of this species are not at present distinguishable from those of $L$. choti, and as records of $L$. triacantha from Venezuela and Colombia are based on females, our male represents an extension of the known range of this species to the northwest (Young \& Duncan 1994). L. reducta has not previously been reported from the Brazilian Rio Negro region, and the record of $L$. olmeca nociva represents the northwestern extreme of the currently known range of this taxon. L. mangabeirana has previously been reported only from the type local- ity in the State of Roraima, Brazil, and L. bettinii was known only from Venezuela.

\section{ACKNOWLEDGEMENTS}

To Dr Marcus Barros (Fiocruz), and Universidade do Amazonas (owners of the vessel WW Kellogg) for logistic support for NFF; to Drs Wilson Alecrim, Antonio Tavares (IMT-AM) and Dr José Alberto Nunes de Mello (INPA) for support and encouragement. To the $5^{\circ}$ BIS battalion of the Brazilian Army for logistic support for TVB in São Gabriel. All figures are by Artêmio Coêlho da Silva (INPA).

\section{REFERENCES}

Feliciangeli MD, Ramirez Perez J, Ramirez A 1988. The phlebotomine sand flies of Venezuelan Amazonia. Med Vet Ent 2: 47-65.

Fraiha H, Shaw JJ, Lainson R 1971. Phlebotominae Brasileiros - II. Psychodopygus wellcomei, nova espécie antropófila de flebótomo do grupo squamiventris, do sul do Estado do Pará, Brasil (Diptera, Psychodidae). Mem Inst Oswaldo Cruz 69: 489-500.

Martins AV, Maciel CS, Silva JE 1968. Notas sobre os fleobótomos do grupo squamiventris do subgênero Psychodopygus Mangabeira, 1941 (Diptera, Psychodidae). Bol Mus Hist Nat - UFMG - Zool 1: 134.

Ryan L 1986. Flebótomos do Estado do Pará, Brasil. (Diptera: Psychodidae: Phlebotominae). Ministério da Saúde, Fundação SESP, Instituto Evandro Chagas, Belém, Documento Técnico No. 1, 154 pp.

Young DG, Duncan MA 1994. Guide to the Identification and Geographic Distribution of Lutzomyia Sand Flies in Mexico, the West Indies, Central and South America (Diptera: Psychodidae). Associated Publishers, Gainesville, Florida, 881 pp. (Memoirs of the American Entomological Institute, No. 54). 